Journal of Medical Genetics 1989, 26, 590-591

\section{Outcome of de novo balanced translocations ascertained prenatally}

There is evidence in published reports for an increased risk of mental retardation or congenital malformation or both in association with de novo, apparently balanced reciprocal translocations. ${ }^{12}$ However, this is largely based on comparison of incidences of such rearrangements in newborn cytogenetic surveys and mentally handicapped populations. To minimise bias and determine risk accurately, long term follow up of many infants with balanced rearrangements detected by newborn screening is required, but to date only a small amount of data from such surveys is available. ${ }^{3} 4$ Further data derive from the outcome at birth of a small number of pregnancies where a de novo rearrangement was detected prenatally. ${ }^{5}$ However, in these cases there is little information on subsequent mental development. In an authoritative summary of published reports it was suggested that risk of abnormality is up to $10 \%{ }^{6}$ and, in one report, ${ }^{7}$ as many as
$26 \%$ of couples chose to terminate their pregnancy after discovery of a reciprocal translocation.

In the west of Scotland it has been our practice to give a more optimistic prognosis; thus we present follow up data on eight consecutive cases of de novo, apparently balanced reciprocal translocations ascertained prenatally in a series of over 15000 amniocenteses performed between 1972 and 1989.

Translocation breakpoints, indications for amniocentesis, and pregnancy outcome are presented in table 1 . In each case the translocation was observed in all cells examined from at least two separate amniotic fluid cell cultures, and in three cases the karyotype was confirmed by examining a cord blood sample taken at delivery. The translocation was assumed to be de novo in each case because the parents were cytogenetically normal. No attempt was made to test paternity. The probands, ranging in age from 16 months to 10 years, underwent physical examination and developmental assessment. Three children of school age were performing satisfactorily in a class appropriate to their age.

With the exception of case 8 all probands were clinically normal. Case 8 was terminated at 18 weeks' gestation after

TABLE 1 Proband data for the west of Scotland.

\begin{tabular}{|c|c|c|c|c|}
\hline Proband & $\begin{array}{l}\text { Age at } \\
\text { examination }(y)\end{array}$ & Translocation breakpoints & $\begin{array}{l}\text { Indication for } \\
\text { amniocentesis }\end{array}$ & Outcome \\
\hline 1 & $1 \cdot 3$ & $\mathrm{t}(2 ; 14)(2 \mathrm{p} 11.2 ; 14 \mathrm{q} 11.2)$ & Maternal age & Clinically normal \\
\hline 3 & $2 \cdot 5$ & $\mathrm{t}(4 ; 18)(4 \mathrm{q} 25 ; 18 \mathrm{p} 11.2)$ & Raised MS-AFP & Clinically normal \\
\hline 4 & $3 \cdot 1$ & $t(4 ; 16)(4 q 16 ; 16 p 11.2)$ & Maternal age & Clinically normal \\
\hline 5 & 4.9 & $t(1 ; 11)(1 \mathrm{p} 34 ; 11 \mathrm{q} 13)$ & Maternal age & Clinically normal \\
\hline 6 & $6 \cdot 8$ & $t(11 ; 15)(11 q 21 ; 15 q 24)$ & Maternal age & Clinically normal \\
\hline 8 & Termination & $t(8 ; 9)(8 q 1 ; 9 p 1)$ & Raised MS-AFP & Anencephaly \\
\hline
\end{tabular}

TABLE 2 Summary of cases of de novo balanced reciprocal rearrangements with known outcome (after Warburton, cited in reference 6).

\begin{tabular}{|c|c|c|c|c|}
\hline & Total cases & Normal & Abnormal & Abnormalities detected \\
\hline Prenatally detected cases & 60 & 56 & 4 & $\begin{array}{l}\text { Bilateral renal agenesis } \\
\text { Fetal dysmorphism } \\
\text { Not specified } \\
\text { Anencephaly }\end{array}$ \\
\hline Neonatal cytogenetic surveys & 13 & 10 & 3 & $\begin{array}{l}\text { Short stature, } \\
\text { hypospadias, dysmorphism, } \\
\text { speech delay } \\
\text { Remedial teaching at } \\
\text { normal school* } \\
\text { Myoclonic epilepsy, } \\
\text { died aged } 3.9 \text { years } t\end{array}$ \\
\hline Combined total & 73 & 66 & 7 & \\
\hline
\end{tabular}

*Pregnancy complicated by pre-eclamptic toxaemia.

+Pregnancy complicated by antepartum haemorrhage.

Received for publication 13 April 1989.

Accepted for publication 28 April 1989 
anencephaly was diagnosed. The balanced translocation was subsequently detected in cultured amniotic fluid cells and fetal tissues.

If our own data are added to those already published (table 2), then the crude risk of any abnormality after prenatal or newborn detection of a balanced, de novo, reciprocal translocation approaches $10 \%$, but very few infants have been followed past the first year of life. Comparable data from other centres are thus required for improved genetic counselling in this area.

D J Macgregor, S Imrie, and J L Tolmie Duncan Guthrie Institute of Medical Genetics, Yorkhill Hospitals, Yorkhill, Glasgow G3 8SJ.

\section{References}

1 Jacobs PA. Correlation between euploid structural chromosome rearrangements and mental subnormality in humans. Nature 1974;249:164-5.
${ }^{2}$ Funderburk SJ, Spence MA, Sparkes RS. Mental retardation associated with 'balanced' chromosome rearrangements. Am J Hum Genet 1977;29:136-41.

${ }^{3}$ Tierney I, Axworthy D, Smith L, Ratcliffe SG. Balanced rearrangements of the autosomes: results of a longitudinal study of a newborn survey population. J Med Genet 1984;21:45-51.

${ }^{4}$ Nielsen J, Krag-Olsen B. Follow-up of 32 children with autosomal translocations found among 11,148 consecutively newborn children from 1969 to 1974. Clin Genet 1981;20:48-54.

5 McCorquodale MM, Tayel S. Prenatal detection of de novo 1;15 translocation with the same breakpoints as those identified in a previous unrelated case report. Prenat Diagn 1988;8:475-6.

6 Hsu LYF. Prenatal diagnosis of chromosome abnormalities. In: Milunsky A, ed. Genetic disorders and the fetus. 2nd ed. New York: Plenum Press, 1986.

7 Warburton D. Outcome of cases of de novo structural rearrangements diagnosed at amniocentesis. Prenat Diagn (special issue) 1984;4:69-80.

Correspondence to Dr John Tolmie, Duncan Guthrie Institute of Medical Genetics, Yorkhill Hospitals, Yorkhill, Glasgow G3 8SJ. 